\title{
School choice and the city: geographies of allocation and segregation
}

\section{Deborah Wilson*, University of Bristol}

\section{Gary Bridge, Cardiff University}

*corresponding author; d.wilson@bristol.ac.uk

This version accepted for publication in Urban Studies on 12 March 2019.

\section{Abstract}

Urban research has increasingly acknowledged the significance of the social and spatial composition of schools in the broader socio-spatial dynamics of cities overall. With increasingly marketised education systems parental choice of school is a key mechanism affecting wider urban processes such as gentrification. Most research into school choice in cities concentrates on the dynamics of choice (how and what parents say they choose). Fewer studies deal with the relationship between choice and the subsequent allocation of pupils to schools. This paper reports the findings of an international systematic review of the connections between parental choice and pupil allocation in school choice systems across the globe. We find that school choice is associated with higher levels of segregation of pupils from different socioeconomic and ethnic backgrounds between schools. This finding is consistent across all types of choice mechanism, in different countries and cities, and across choice systems that have been in place for different lengths of time. The reasons behind the observed relationship are, 
however, highly localized and contextual, including: particularities of the choice mechanism, social composition of neighbourhoods and mix of school types in a city. Increases in between-school segregation may lead to schools being more homogenous in their social composition, with broader implications for social cohesion and educational inequalities in cities. Relating the findings to the broader urban school literatures we suggest that scales and geographies of allocation are critical in understanding the dilemmas and dynamics of choice, the resultant inequalities, and any proposed interventions or solutions to reduce these inequalities.

\section{Acknowledgements}

The authors would like to thank the Nuffield Foundation (www.nuffieldfoundation.org) for funding this research (project reference EDU/42625). The views expressed are those of the authors and not necessarily those of the Foundation. We also thank and acknowledge Llorenc O'Prey for his contribution to both the research bid and in carrying out the initial literature searches, Dr William Turner for his help and guidance with systematic review methodology, and the anonymous referees, editors and other contributors to this special issue for comments on previous drafts of the paper. All errors remain our own.

\section{Keywords}

School choice; segregation; urban schooling; allocation; equality of opportunity 


\section{Introduction}

There has been increasing emphasis in the urban literature on schools as a critical factor in explaining wider social and spatial relations in the city. The spatial distribution of different types and quality of schools has been seen as a critical component in the dynamics of gentrification, for example, as the urban middle classes shuffle for position to access the 'best' schools (Butler and Hamnett, 2010; Butler and van Zanten, 2007). Researchers have identified how certain circuits of schooling are part of carefully planned educational pathways for social class reproduction and spatial pathways through the city (Ball et al. 1995). The relationship of school composition to neighbourhood composition has been explored, particularly in the context of urban policies that promote the idea of social mix (Oberti, 2007; Bridge et al., 2011). With education policy changes in many countries over the last 30 years moving towards a more market-like arrangement, in which schools compete for pupils and parents choose schools (within certain supply constraints), the issue of school choice has become much more significant in understanding socio-spatial relations in the city.

Despite its political popularity, parental choice of school and its effects is a somewhat contested field. Exponents have variously argued that school choice can increase equality and educational attainment in education by breaking the geographical link 
between pupil and school (seen as a source of inequality in a catchment based system) and by raising the quality of schools via competition for pupils. Critics of choice have countered that it in fact standards have not been raised and there is still middle class advantage in the education market (Burgess et al., 2011; Fowler, 2002). Both sides have claimed to hold the theoretical and empirical imperative (Bridge and Wilson, 2015), while the evidence to support either side is much less conclusive (Wilson, 2013). The lack of conclusive evidence reflects the complexity of the policy landscape and the difficulty in isolating the effects of 'choice' relative to alternative allocation mechanisms. In practice, different choice-based allocation mechanisms have variously replaced, or been introduced alongside, alternatives such as neighbourhood schooling (each pupil goes to their local school), or academic selection based on exam performance, or selection by income into private schools (Burgess, 2016). While choice is a commonly used term in current policy discourses, therefore, the outcomes of any specific choicebased mechanism for different types of pupil in different geographical locations depend on the institutional design of admissions policy, the organisational culture, and the incentives thereby created for the different actors involved (families, schools, local and national government).

The ways in which different types of pupil are allocated or 'sorted' across different 
schools is a key outcome of school choice. School peer groups are widely thought to be important for children's development and their academic progress (Atkinson et al., 2008). If peer groups matter, the ways pupils are sorted across schools has implications for educational trajectories and outcomes as well as equity of access (Burgess et al., 2007). Moreover, as well as determining the composition of each school's student body, pupil sorting potentially has knock-on effects on neighbourhood composition, often via the links between the housing market and the 'market' for schools (Fack and Grenet, 2010 and references therein). The mechanisms of choice and allocation also influence the relationship between residential segregation and school segregation in cities.

There are two stages to sorting. The first is the residential choices by parents who include (or are able to afford to include) school choice as part of their selection of home neighbourhood in order to have potential access to high performing schools. The second is any additional sorting that occurs as a result of the school choice mechanism. The two stages are of course linked: given that parental choice of home location is partly based on the chances of securing a place at their most preferred school, changes to the mechanism by which such places are allocated will affect that decision (Burgess, 2016). Our review does not explicitly consider these interconnections; rather our findings provide evidence on whether policies such as open enrolment exacerbate or reduce the 
sorting patterns that have resulted from residential mobility. Before outlining our methodology and data analysis in detail we therefore review the broader urban literature on school choice and show how our findings contribute to this.

\section{Urban research on school choice}

There have been different foci of research into school choice in the urban context. One area of investigation has been into parental choice itself, with a focus on what parents say they choose and their reasons for doing so. Much of this research has been qualitative and much of it is from a perspective using sociologist Pierre Bourdieu's arguments concerning the relationship between economic, social and cultural capital in social (mainly class) reproduction (Ball and Vincent, 1998; Ball et al 1995; Ball 2003 Raveaud and van Zanten, 2007; Butler and Hamnett, 2010; Bridge 2006). Another cluster of research has been into school segregation and school composition (Burgess and Wilson (2005) and references therein). In some cases school segregation has been investigated in the light of the much larger literature on residential segregation in urban neighbourhoods and the relationship between the two (Frankenberg 2013; Bonal and Bellei 2018: Burgess et al., 2005). Related to this there is also a substantial literature in urban studies that deals with the impacts of the influence of school choice and perceived school quality on residential trajectories and neighbourhood selection, particularly for 
the middle classes (Bernelius and Vaattovaara, 2016; Van Zanten and Kosunen, 2013). This literature tends either to tie together statistical associations of residential segregation with school segregation (Boterman, 2013) or, at a more qualitative level, to explore the choices of middle-class parents in terms of residential mobility and how school choice affects that residential choice. It suggests that there is a strong relationship between residential choice and school choice, certainly for middle class parents who can afford the higher house prices that result from the desirability of being in the catchment of a 'good' school; prices that, in turn, are an outcome of those preferences (Gibbons and Machin, 2003; Fack and Grenet, 2010). According to this literature the association between school choice systems and residential sorting (and segregation) applies across different national, urban and institutional differences, even in the context of the more egalitarian and open school choice context of the Netherlands (see Boterman's paper in this special issue). Central to this finding is the ongoing reliance of proximity to school as a key element of choice-based allocation mechanisms, particularly for popular, over-subscribed schools (Burgess et al., 2015).

These literatures on residential segregation and school segregation have tended to be more quantitative in orientation - crossing the economics, geographical and sociological literatures. There is also a large literature on the effects of school choice and subsequent 
performance in terms of pupil and school test score outcomes, again largely quantitative in nature, and generally influenced by economic and rational choice models, even if sometimes implicitly (Allen and Burgess, 2010; Burgess, 2016). This is substantiated by a more explicitly rational choice sociological literature that sees school choice and class reproduction, not as the exercise of superior social and cultural capital by middle class families, but as the outcome of different assessments of risk of certain educational choices conditioned by a hierarchical class structure (Goldthorpe 1996; Breen and Goldthorpe 1997; Bridge and Wilson 2015)

Thus taken overall, in the urban literature on school choice the research focus has been on the dilemmas of choosing (investigated qualitatively) or the association between residential segregation and school segregation (using quantitative data). Less attention has been paid to the effects of the various mechanisms of school choice themselves, especially in relation to how they affect the allocation of pupils across schools. This paper seeks to address this gap in the evidence base through a research review that isolates those studies that include the stages of the school choice process from parental choice through to final allocation of students to schools at the individual or household level. The research question used in this systematic review was: 
What does research tell us about the effects of choice-based admissions policies on the allocation of pupils to schools, with regard to (i) different types of pupils (socioeconomic status, ethnicity; faith; ability); and (ii) different types of choice-based admissions policies and institutional structures.

Our analysis is based on an international, systematic, cross-disciplinary review of the research evidence on the effects of choice-based mechanisms on pupil allocation to schools, encompassing the broad range of different choice mechanisms employed in different national and state contexts. A key point to note is that all of this research on choice and allocation is conducted in cities and/or reports at a national level using urban-level data. This is not surprising: it is in cities where there is a significant level of choice between schools and competition between them for pupils, sometimes with several choice-based allocation mechanisms operating simultaneously. The review also deals with a range of pupil characteristics (socioeconomic status, ethnicity, faith, ability). As discussed above, we situate the findings of our analysis within the broader literature that relates the dynamics of school choice with the related issues of residential mobility, neighbourhood composition and social mix.

There are a number of advantages offered by this systematic form of analysis. It isolates 
research that explicitly links parental choice and pupil allocation; it isolates those studies that deal with these issues at a pupil/household level, i.e. at the finest level of discrimination of data, looking at choice and allocation at the household level (rather than using district or more aggregate level data sets); it deals only with rigorously designed studies, with robust methodologies based on large, often administrative, data sets; and it includes and isolates studies that have experimental or quasi-experimental designs (such as before and after studies).

\section{Methodology and data analysis}

In order to deliver the objectives set out for this research, we undertook a systematic review that included research from all social science disciplines, situated across all potential national contexts. We were purposely broad in scope and sought to pull together all the existing research on our particular topic, analysing trends, finding common themes and identifying limitations in that body of scholarship. In designing the project methodology, we drew on guidance from the literature on integrative review methodology (Cooper, 1982; Jackson, 1980; Whittemore and Knafl, 2005), which enabled us to take a more expansive view of the types of research that can be included, considering experimental and quasi-experimental research, in-depth qualitative studies 
and observational studies including correlational designs. We also extended our search to include theoretical papers relevant to our key questions. ${ }^{1}$

The breadth of the scope of our review is reflected in the broad definition of school choice we used as a starting point for our search strategy:

Choice-based admissions policies are those which seek to provide families with a degree of discretion in the selection of the school their children will attend. This includes policies that give families at least two options, with parents able to express a preference regarding which school they would like their children to attend.

Given that broad definition we employed clear inclusion and exclusion criteria to create boundaries for our search in what is an extremely large body of related work. For a study to be included in our dataset, it had to include information on all of the following:

Inclusion criteria:

\footnotetext{
${ }^{1}$ As we discuss below, however, due to the exacting nature of the data required for studies focusing on our specific research question, the papers that comprised our final dataset all employed quantitative methodologies.
} 
- Choice-based admissions policy (as defined above) within a predominantly statefunded education system;

- Compulsory education (primary or secondary school choice or equivalents);

- Final allocation of pupils to schools;

- Pupil and/or family socio-demographic characteristics (socioeconomic status; ethnicity; faith; ability).

The primary unit of analysis, therefore, is the family. There is some grey area over this in the literature: some studies, for example, use pupil-level data on some characteristics (for example ethnicity; gender), combined with family-level data on others (for example, income; parental education). This is then sometimes aggregated to school level. We therefore included studies that aggregate pupil and/or family level data in order to compare allocation of different pupil types across schools.

Similarly, we defined clear exclusion criteria, which formed the basis on which we took decisions to exclude studies from our dataset:

Exclusion criteria:

- Theses, dissertations, commentaries, editorials; 
- Non-English language texts;

- Research that 'only' considers the effect of school choice on pupils' attainment (including choice of within-school tracks);

- Level of analysis at district / local authority level or above (for example national or cross-country analyses).

There are three points to note regarding the consequences of our search criteria. First, our exclusion of non-English language texts inevitably skews the dataset towards Anglo Saxon countries. As we show in the next section, however, our dataset does include studies from a range of cities and countries across the Global North and South. Second, we explicitly focused on choice-based admissions policies within a predominantly statefunded education system. We didn't include studies that solely focus on parents choosing private schools per se; but our dataset does include state-funded school choice systems within which the choice of a private school - via the use of a voucher, for example - is one option for parents. An analysis of public-private schooling differences, or the differences in private schooling across different national contexts, is therefore outside the scope of this paper. ${ }^{2}$ Third, the research that includes both details of the

\footnotetext{
${ }^{2}$ Burgess (2016) discusses the economics literature on choice of private school. He refers to the OECD (2012) report that both highlights the variation of private school attendance across OECD countries and
} 
school choice mechanism and final allocation of pupils to schools is quantitative. This is in part a result of the exacting nature of the data required: to include choice and allocation at a household level but with sufficiently large data sets to elicit patterns of choice, allocation and resulting sorting across schools.

The search strategy combined electronic searches of a broad range of general and specialist databases, supplemented by hand searches of the bibliographies, reverse citation mapping of relevant studies and an additional searches of the relevant grey literature. The initial search strategy yielded a total of 559 studies. Two rounds of screening, adhering to systematic review protocols, was undertaken by both authors. At the first screening stage both authors independently screened titles/abstracts of all 559 studies against the above inclusion and exclusion criteria, with discrepancies discussed on a case-by-case basis. 169 studies were taken through to the second stage. Both authors independently analysed the full text of all 169 studies to determine whether they fully fitted all the inclusion criteria. All discrepancies were again discussed on a case-by-case basis. This yielded 64 papers that formed the final dataset.

shows that the socio-economic stratification across schools is associated with the level of public funding to, and not prevalence of, private schools. 
Data extraction was carried out by both authors after a process of moderation and following systematic review protocols (Pawson et al 2005; Whittemore and Knafl 2005). Categorizations for the extraction were agreed a priori and the results inputted into a shared excel spreadsheet. Key elements of the data extraction included: geographical location; pupil/family characteristics; stage of education; research design; details of specific school choice mechanism; final pupil allocation; results. The full list of categories is available in Table A1 of the technical appendix that accompanies this paper. Each study was additionally assessed for methodological rigour and theoretical consistency according to pre-defined protocols. These included criteria of consistency of theoretical exposition and degree of consistency between theoretical approach, research design and interpretation of findings, as well as categorisation of papers in terms of robustness of research design, data measurement specification and threats to validity (details in Tables $\mathrm{A} 2$ and $\mathrm{A} 3$ in the technical appendix).

Data analysis in research reviews 'requires that data from primary sources are ordered, coded, categorized and summarised into a unified and integrated conclusion about the research problem' (Whittemore and Knafl, 2005: 550). There is inevitably some degree of subjective interpretation when analysing the data from such a broad range of primary sources (Cooper, 1982), hence the need to be explicit regarding both the categorization 
rules by which the data has been extracted (above and Tables A1-A3) and the principles guiding the subsequent analysis.

Our core focus was the relationship between key elements of the choice system and the final allocation of pupils to schools, focusing primarily on differences across socioeconomic status and ethnicity. We employed an iterative process of examining the primary data in order to identify patterns and relationships between these. Here we drew on realist synthesis approaches (Pawson et al., 2005; O'Campo et al., 2015) which aim to identify how a particular programme - here, school choice - works for whom and under which circumstances. We first identified patterns across the different school choice mechanisms investigated in the studies, which enabled us to thematically code each study within two broad classifications of school choice: opt out and open enrolment, discussed below. This further enabled initial geographic classifications in terms of where different forms of school choice are employed at a national, regional and city level. Within these broad categorisations we identified three key elements common across each: type of schools to which pupils are allocated; process of allocation; method of payment: all discussed further below. We then reviewed the studies in terms of the pupil/family characteristics employed to draw out patterns of the differential effects of school choice allocations across socioeconomic status and ethnicity (faith was 
also a characteristic investigated but by a much smaller subset of studies). Together, these iterative processes of examining the primary data enabled us to identify patterns and relationships between the key elements of different choice mechanisms and the final allocation of pupils across schools.

\section{Results}

\section{An initial mapping of the research literature}

Our systematic review yielded a dataset of 64 papers (full list of papers available as part of the Technical Appendix). While the disciplinary spread of the studies across social sciences is quite broad, encompassing economics, education, geography, sociology, policy studies and management, all 64 papers employed quantitative methodologies (multivariate regression analyses; quasi-experimental research design; simulation modelling, for example). Most studies were based on large administrative datasets that included final allocation data; a minority analysed large scale household surveys. The requirement to analyse studies that included both choice and allocation, at household level but with sufficient numbers to establish robust patterns, resulted in this discrete slice of the literature. The inclusion/exclusion criteria involved to achieve this selection meant that some of the more familiar studies on urban schooling and parental choice 
(such as the large qualitative literature on the dynamics of parental choice) were excluded from this review.

Pupil or household characteristics were mostly defined by socioeconomic status (SES) and/or ethnicity. Ethnicity and 'race' was particularly prominent in US studies which is unsurprising given the concerns with residential segregation of African Americans in US cities. Pupil ability was an element in 19 of the 64 studies but alongside measures of SES and ethnicity (except for two ability-only studies). Ability does not feature strongly in the findings we report from the studies in this review because our particular focus was on the effect of choice on allocation rather than subsequent attainment (where discussions of ability peer effects feature much more). Six studies included faith but again alongside SES and ethnicity. In these cases (predominantly the Netherlands and Germany) allocation to denominational schools has been much more typical in the past.

There are numerous school choice systems internationally, as well as different systems sometimes operating within the same national context: there is considerable variation across the states of America in terms of their organisation of school choice and other education policies, for example. We explicitly did not set out to map and describe the institutional details of individual school choice mechanisms and policies in each context. 
Rather, our aim was to take a broader overview; to look across these different systems in order to draw out common elements, themes, outcomes: this is one of the key added values of our chosen methodology. Here, therefore, we list these common elements across the two broad categorisations of school choice system that we derived from our analysis; 'opt-out from geographically assigned state school', and 'open enrolment'. For 'opt out' the starting point is essentially neighbourhood schooling, i.e. pupils are initially assigned a school on the basis of their place of residence. For 'open enrolment' families are able to express a preference for the school(s) they would like the child to attend. Such preferences may be constrained by the range of schools available in practice, and/or may not be realised, due to the various constraints on capacity, travel etc. Our categorisations mirror the two types of school choice system that Burgess (2016) distinguishes, respectively an individual entitlement to attend a different school to your current one, and a systemic market rule for assigning all pupils to schools. While necessarily broad, the aim is to capture key features within - and constraints across these categorisations.

Table 1 summaries the key features of our categories of school choice system, along with information on where these systems are employed, by nation, region and city. The evidence on the effects of different 'opt out' mechanisms, for example, is 
overwhelmingly based on the US experience; while 'open enrolment' is employed across a much broader range of countries.

[TABLE 1 APPENDED ON PAGES 44-46]

There are several constraints that cut across both these broad categories of school choice systems. One is the limited capacity of (at least some, popular) schools, leading to the need for over-subscription criteria by which places at such schools are allocated. Straight-line distance from a family's residence to the school is a common criterion of allocation in case of over-subscription. This re-introduces a geographical component to allocation that the parental choice system was often intended to counter. It therefore re-establishes the capacity of superior choice for higher income families who can afford property close to oversubscribed schools. Those schools tend to be high performing (though this isn't always the case) and so the inequalities are compounded. The specific geographical context also determines the particularities of each family's choice set and the range of schools from which they can choose. This can include not just the number and type of schools available for choice, but also what is effectively available in terms of accessibility by public transport (if necessary). The number of oversubscribed schools in a choice set also affects parental choice in practice, especially for lower income families 
who can't buy the often more expensive property closer to these popular schools. The socioeconomic context therefore places differential constraints on families in terms of their residential location; travel costs to alternative schools; ability to pay any required 'top-up' or other costs to attend their school of choice. Even the built form of the city (roads, intersections, safe routes for children) can influence how and to what extent certain schools figure in the feasible choice set for different families.

\section{Research evidence}

The objective of this systematic review was to encompass the full range of geographical contexts and school choice mechanisms in order to identify common themes and/or patterns in the impact of school choice on the sorting of pupils across schools at different national, regional and urban spatial scales. As discussed above, the review involved explicitly looking across systems within each of our categorisations and then drilling down to specific regional and especially urban contexts in order to test out any emerging patterns by different pupil/household characteristics. With reference to Table 1 , therefore, we start by discussing the findings from studies in each of our categorisations in turn, before drawing out the common themes we subsequently identify across these different categories and geographies. In the discussion that follows the numbers refer 
to the unique identifier for each study in the dataset, as detailed in the Technical Appendix.

\section{Open enrolment}

Some of the strongest evidence on the effects of open enrolment systems comes from Chile, which introduced school choice in a nationwide policy reform in 1981. Public schools were transferred from central to local government and parents were given 'total freedom' [34; page 201] to apply to any subsidized private or public school, which in turn received a per-student voucher. Schools were free to select pupils from the pool of applicants (we return to this point below).

As detailed in Table 1, there are six papers in our dataset that investigate the effects of that reform, at national [30; 54; 72], regional [67] and city level [34; 154 - both Santiago]. Together these provide a strong body of evidence on the effects of an open enrolment school choice mechanism on the socioeconomic sorting of pupils. This is for two reasons: first, the research designs are robust, exploiting the nationwide introduction of the same school choice system using primarily multivariate regression analyses including regression discontinuity methods and simulations. Second, the 
papers provide evidence of the effects of the same nationwide policy reform at different geographical scales: national, regional, city.

The clear finding from this set of papers is that school choice increased social segregation across schools in Chile. This is over and above residential segregation patterns [72], thus showing the additional impact of school choice on segregation, and with little related evidence of any improvements in test score outcomes [54; 67]. But what is underlying this result in the Chilean context? This body of evidence suggests a combination of parental preference and school selection, both working towards increased social stratification. One of the Santiago studies [154] analyses survey data to investigate parents' stated preferences (what they say they want in interviews or on surveys) and revealed preferences (what they actually choose on the school choice form) across schools, and shows that, while few cite social class as a choice factor, most include only schools with similar student demographics in their choice sets. This is a broader theme we discuss in more detail later in the paper. [54] argues that schools have responded to the reform by selecting certain types of student (with higher socioeconomic status or ability) rather than raising productivity (measured in pupils' exam scores and other performance management measures), highlighting the need to regulate admissions criteria. Again, we return to this below. 
Another strong body of evidence comes from the school choice system that has been in place in England and Wales since the national reforms of 1992, which introduced open enrolment, local management of schools and per capita funding, with the funding following the pupil's allocation. The majority of papers from England use the same national, pupil-level administrative data which links pupils to their school and records their test scores at different key stages. This annual census also includes pupil characteristics such as free school meal eligibility (widely used as an indicator of socioeconomic status) and ethnicity and, crucially, pupils' home postcodes, which enables detailed analyses of the effects of choice on residential and school segregation across different urban contexts. The English evidence base in our dataset therefore uses the same data and pupil indicators in a range of robust, multivariate, predominantly econometric and geo-spatial research designs.

The findings from the majority of studies of the English open enrolment system corroborate those from Chile: school choice is associated with increased socioeconomic segregation across schools $[165 ; 158 ; 16 ; 17 ; 168 ; 84]$. Central to these results is the finding that between-school segregation levels are higher than those presented by residential patterns $[17 ; 16]$ again pointing to the additional effect of choice systems on segregation. This is also found to be the case in a geo-spatial study of ethnic segregation 
in Birmingham and London [46], for example, particularly for pupils of Black Caribbean heritage. It is worth noting two papers that do not corroborate this finding. An analysis of school segregation indices for English and Welsh schools through the 1990s finds no evidence that segregation has increased as a result of school choice [42]. The authors of the study suggest that further analysis at lower levels of aggregation is required for a detailed explanation, incorporating the diversity of schools and admissions policies. [44] is an example of a study that does that: an early analysis of the introduction of free schools in England. The study's authors find no evidence of difference between the social composition of (secondary) free schools compared to the national average but argue that this is due to two effects balancing out: free schools are socially selective within their neighbourhoods but are located in areas of above average social disadvantage. Together these studies highlight the need to consider local context to explain observed patterns; a more general point to which we return later.

Two further results from the English open enrolment system are worth highlighting. First, there is evidence of social polarisation in school populations, with the most popular schools in a district gaining a more advantaged intake and vice versa [169]. [18] reinforces this message with its finding of systematic differences in the sorting of low and higher income pupils between low quality and high quality schools. Second, a careful 
study of the urban district of Brighton and Hove [168] employed a 'before and after' research design to investigate the effects of replacing proximity-based allocation with a lottery in the case of oversubscribed schools. The authors' prior hypothesis was that this policy change would lead to lower socioeconomic segregation, with the lottery weakening the link between residential location (and house prices) and allocation to popular, oversubscribed schools. Their hypothesis was not supported by the results, however, which they ascribed to the way catchment areas had been re-drawn as part of the reform. The design details of the school choice mechanism - here, the drawing of the geographical boundaries within which lotteries across schools will be held - matters; we return to this point below.

As Table 1 illustrates, the 'open enrolment' school choice system operates in a wide range of countries across the world. Our review therefore provides evidence of the effects of this choice mechanism across a broad range of contexts at different geographical scales: national; regional; city. There is evidence on the effects of open enrolment on ethnic segregation between schools from Sweden [11; 13; 93], Germany $[79 ; 58 ; 103]$ and the Netherlands [25; 57]. In Spain [66; 156], open enrolment is shown to increase SES segregation between state schools and those private schools incorporated into the state-funded choice system, with the authors of the Aragon study 
[66; page 105] arguing that 'positive discrimination measures in favour of the least welloff families' will be needed to facilitate school choice across all sociodemographic groups. Other studies highlight specific points which have wider relevance for the operation of school choice systems. The Zimbabwe study [114], for example, notes the fundamental constraints on choice for rural communities; while a study from Cape Town [51] shows little relationship between choice and SES, which the author explain through school choice reflecting racial history and perception of opportunity in the current South African context.

\section{Opt out}

The vast majority of the evidence on 'opt out' school choice mechanisms included in our dataset comes from the USA. This evidence builds on and complements that from open enrolment in several ways. First, the focus of the US literature is on changes in segregation by ethnicity as well as by socioeconomic status. Second, there is a range of different mechanism designs within the broad 'opt out' framework that enable us to build a broader picture of the effects on pupil allocation of alternative school choice policies. In particular, a key distinction is whether the opt out program is targeted at a specific sociodemographic or is more universally applied. As above, we present the broad results of the systematic review, illustrating them further by drilling down into 
particularly robust examples (in terms of the quality of the data sets and sophistication and rigour of methods/analysis - see technical appendix) across different cities and/or geographical levels.

There are fourteen papers in our dataset that investigate the effects of charter and/or magnet school choice on pupil allocations, across a range of US geographies, both in terms of scale and location. Three are national $[118 ; 131 ; 27]$; five at state level [North Carolina 8; Texas 122; Michigan 130; Arizona 35; 36] and six at city or county level [Washington DC 55; Indianapolis 65; Durham NC 9; Montgomery County, Maryland 160; Philadelphia 78; San Diego 133 (we discuss this last study further below)]. The overriding result across all these studies is that the charter school program in particular has exacerbated between-school segregation by both socioeconomic status and ethnicity. There is a clear distinction between these schemes and the more targeted design of some of the magnet school programs. However, even though the latter are often designed and targeted to explicitly reduce segregation, the three city level studies in our dataset [Montgomery County 160; Philadelphia 78; San Diego 133] all show that this is not the end result; specifically that any decreases in segregation for magnet schools are outweighed by greater segregation overall in neighbourhood schools. 
This pattern is corroborated by the studies in our dataset that focus on US voucher programs, all of which use national data. [157] uses national survey data in a multivariate model to simulate the effects of voucher introduction and reports that 'startling differences between movers [families that opt out to another school] and stayers [that accept their designated school] exist with regard to family income, whether parents attended college, and race' [157, page 304]. The authors state, therefore, that they expect a universal voucher policy to exacerbate economic and racial segregation in urban public school environments. Even the studies investigating vouchers targeted at low-income families reveal a mixed picture, again across geographical scales and locations [national 135; Florida 139; Milwaukee 24; New York 134], with some evidence of differences across both income and ethnicity at application and/or enrolment stage. In Milwaukee [24], for example, there is no stratification by SES at application stage, whereas there is at the point of enrolment. The authors attribute this to the costs (of transport, for example) associated with enrolling at a non-neighbourhood school.

Overall, therefore, the picture that emerges from this section of the evidence base is that even targeted schemes are not wholly successful at reducing segregation, and more universal schemes are actively associated with an increase in segregation, with respect 
to both social class and ethnicity. A closer look at three key studies in different urban contexts reveals more about what is underlying these results.

Koedel et al (2009) [133] evaluate the integrating and segregating effects of three distinct school choice programs in the same city (San Diego Unified School District); two explicitly designed with integration as an explicit objective; the third a state-mandated, open enrolment program. The authors find that the former two increase integration whereas the latter segregates the district's schools. Issues of access - and in particular travel constraints - are shown to be key in this context: the integrating programs provide transport for student participants while the open enrolment program does not. Disadvantaged students are underrepresented in the open enrolment program. Given that all choice applicants choose schools with more socioeconomically advantaged peers (in turn, correlated in this context with choosing 'more White' schools), this provides one explanation for the observed differences in outcomes across the programs: participation by disadvantaged students tends to increase integration, while their nonparticipation exacerbates the tendency towards increased segregation. This effect is corroborated by evidence from an opt out system in Germany [88]. We discuss this further below. 
The effects of the underlying preferences of parents and students are also emphasised in two studies that investigate the charter school system in North Carolina - at state and city (Durham, NC) level [8; 9]. Both papers find charter schools are associated with higher levels of segregation; with higher effects across income than ethnicity in Durham, NC [9]. The patterns underlying these results are somewhat nuanced, however. In both papers the authors find that White students are more likely to make segregating choices, while the observed segregating choices by Black students are in fact sometimes driven by the lack of more mixed alternatives within their neighbourhood. Echoing Koedel at al (2009 [133]) the authors [9] conclude that the integrating effects of choices by disadvantaged students seeking higher achieving schools are outweighed by the segregating effects of choice from their more advantaged peers. Both underline the importance of the constraints in driving the observed outcomes; fundamentally linked to residential segregation patterns in the specific urban context, the mix of schools from which to choose within the locality, and the cost of transport required to access alternatives further afield.

\section{Core findings}

The consistent finding across the data from the review is that school choice is associated with higher levels of segregation of pupils between schools. It is consistent across 
different types of choice mechanism, as categorised by 'open enrolment' and 'opt out'. ${ }^{3}$ It is also observed in a wide range of different national, regional/state and city contexts and across systems that have been in place for varying lengths of time. The finding also holds across a range of socio-demographic characteristics against which segregation is measured: socioeconomic status, ethnicity and faith (although this last finding is based on a much smaller subset of studies). Higher measures of segregation are also consistent across the different systems of allocating places to schools that are over-subscribed, including allocation by residential proximity, or through the operation of a lottery, which has been shown to be sensitive to how the boundaries are drawn.

This is a surprisingly consistent result, given that our review encompassed such a broad range of choice systems, geographical locations and timeframes. It is consistent across different urban contexts and their contextual complexities of choice system(s); size of school districts/catchments; the number of schools and degree of competition in the area, and the existing socio-economic geographies of the neighbourhoods involved.

More generally, the finding that school choice is linked with higher levels of betweenschool segregation leads to the question of 'relative to what'? What is any one current

\footnotetext{
${ }^{3}$ Not including some specific, targeted, magnet school programs in the US, as discussed.
} 
system of school choice being compared to, in terms of resulting outcomes? Again there was a range of scenarios that the studies we reviewed had investigated and which employed a range of robust methodologies to control for both observed and unobserved confounders in order to isolate the effect of school choice. The studies investigated the allocation of pupils to schools under a school choice mechanism relative to: the policy that pre-dated school choice being introduced [see, for example, 49; 82]; a comparison of geographical areas that have more choice options relative to other areas where choice is more limited [46]; the introduction of vouchers that provide pupils with a choice of school other than the one to which they had been assigned [135] and the residential levels of segregation observed in a system of location-based school assignment $[11 ; 84]$. In comparison to the range of alternative allocation mechanisms investigated by the research we reviewed, the consistent finding is that school choice is associated with higher levels of between-school segregation.

Although choice is associated with higher segregation between schools across all the different choice mechanisms included in our review, the reasons why this is the case were more contextual. The size of the school district, number of schools, particularities of the choice mechanism, composition of neighbourhoods - are all discussed in the different studies as contributing to the resulting allocation, reflecting the importance of 
context and the particularities of school choice. Context may include historical factors, such as the apartheid legacy in South Africa [51] or the history of racial residential segregation in the US [9], resulting in segregated choice sets in many locations. Equally, prior residential sorting or the differentiation of feasible choice sets for lower income families in England indicates the significance geographical and socioeconomic factors in understanding processes and outcomes of choice in different localities [17]. Parental preferences are undoubtedly part of the story, and the studies in our dataset reveal differences across both socioeconomic status [154] and ethnicity [133]. But it is not only differences in preferences that are driving the observed outcomes. The outcomes of any choice-based mechanism are a result of a combination of factors, including system design, constraint, lack of information, as well as any parental preference. These combinations of alternative, non-mutually exclusive, explanatory factors in what is a consistent result across the evidence base partly reflects the problems of identification discussed earlier.

The final overall finding is that school choice may lead to more homogenous school composition. This finding is a consequence of the first: segregation and composition are linked, in that segregation results in more homogenous school composition. Again, however, there are various reasons behind this discussed in the research. Some choice 
systems exacerbate segregation though competition in cases of over-subscription: for example the use of a proximity criteria in an open enrolment system may mean that middle class households are able to gain admission to certain schools through being able to afford to move near such schools [17]. In an opt-out system there may be a double effect on school composition: studies of the charter school system in the US found that this system exacerbates between school segregation and homogeneity of composition with respect to both the charter schools moved to and the public schools that are vacated [78].

The studies included in our review mostly focused on the segregation in allocation issue rather than on the type and quality of destination schools. However from the evidence that was available on the types of school to which pupils are allocated, there are studies across several countries that suggest that in systems of school choice, disadvantaged pupils are over-represented at more poorly performing schools [18].

\section{Discussion and conclusion}

The consistency of the result of higher levels of segregation across schools in school choice systems, despite differences in system design, geography or duration, is striking. The preceding discussion of the broader urban schooling literatures further emphasises 
our second finding that the reasons behind this observed relationship are localised and contextual. We can, however, draw out some implications for policy from our findings. First, school choice is not the policy instrument by which the integration of pupils across schools, by socioeconomic status, ethnicity or faith, can be achieved. Second, given the importance of local context, any system of school choice needs to take account of, and be sensitive to, these local variations in the overall allocation of pupils to schools. Third, because the reasons for the observed increases in between-school segregation of pupils are localised and contextual, relating to geographical areas of school choice that are at a greater scale than individual school catchments, the coordination of admissions (including schools that are oversubscribed) should be conducted at an urban municipal / local authority (or equivalent) level, rather than being at the discretion of individual schools. A further finding in cases of over-subscribed schools is that even if a lottery, rather than other over-subscription criteria, is employed, the evidence reviewed suggests that segregation of pupils across schools may still increase. The evidence suggests that boundary drawing to ensure heterogeneity in lottery allocation is key.

This analysis of the effects of choice and allocation in urban schooling systems also reveals a number of possible avenues for future urban research in this field, some of which merit mixed-methods approaches. The first would be to build on the substantial 
qualitative evidence on parental choice to explore the effects of final pupil allocation (and the extent to which that reflects parental preferences) on urban households, across both socio-demographic and ethnic characteristics. The degree to which patterns of allocation, particularly in opt out systems, influence residential choice patterns over time, and potentially involving new paths of gentrification, is another possible area of research. Given the relatively limited nature of the evidence base identified and analysed in this paper, the effects of alternative school choice mechanism designs in an urban context more generally merits further research. The impacts of other design instruments (beyond opt out and open enrolment), such as positive discrimination for high deprivation postcodes in school selection, additionally warrants investigation, both at a quantitative and qualitative level.

The results of this systematic review provide an overview of the effects of a range of school choice systems on the allocation of pupils to schools. Allocation mechanisms are a vital link between socio-demographic residential patterns and the pupil composition of different types of school in an urban area. It is clear that these mechanisms have their own impacts on the resulting spatial distribution and social/educational situation of pupils across schools. The introduction of school choice mechanisms can also impact on residential sorting prior to choice. In all this the particular urban context is critical: its 
social geography, the particular policy mix and the institutional and geographical 'space' for the allocation of pupils. This paper suggests that a keen attention to these scales and geographies of allocation is critical in understanding the dilemmas and dynamics of choice, the resultant inequalities, and any proposed interventions or solutions to reduce those inequalities. 


\section{Bibliography}

Allen, R and Burgess, S (2010) The future of competition and accountability in education, http://www.2020publicservicestrust.org/publications (accessed 16/01/16).

Atkinson A, Burgess S, Gregg P, Propper C and Proud S (2008) The impact of classroom peer groups on pupil GCSE results, CMPO Discussion Paper 08/187, Bristol: CMPO.

Ball S (2003) Class Strategies and the Education Market: The Middle Classes and Social Advantage. London: Routledge Farmer.

Ball S and Vincent C (1998) 'I heard it on the grapevine': 'hot' knowledge and school choice, British Journal of the Sociology of Education. 19(3): 377-400.

Ball S, Bowe R and Gewirtz S (1995) Circuits of schooling: a sociological exploration of parental choice in social class contexts. The Sociological Review 43(1): 52-78.

Bernelius V, and Vaattovaara M (2016) Choice and segregation in the 'most egalitarian' schools: Cumulative decline in urban schools and neighbourhoods of Helsinki, Finland. Urban Studies, 53(15): $3155-3171$.

Bonal X, Bellei C (eds) (2018) Understanding School Segregation: Patterns, Causes and Consequences of Spatial Inequalities in Education. London: Bloomsbury Academic.

Boterman W (2013) Dealing with diversity. Middle class family households and the issue of black and white schools in Amsterdam. Urban Studies 50: 1128-1145. 
Breen R and Goldthorpe J H (1997) Explaining educational differentials: Towards a formal rational action theory. Rationality and Society 9: 275-305.

Bridge G (2006) Perspectives on the neighbourhood and cultural capital Urban Studies 43: 719730

Bridge G and Wilson D (2015) Towards an interactive sociological rational choice approach to theorising class dimensions of school choice. Policy and Politics 43(4): 493507.

Bridge G, Butler T, and Lees L, (eds) (2011) Mixed Communities: Gentrification by Stealth? Bristol: Policy Press.

Burgess S (2016) Human capital and education: the state of the art in the economics of education, IZA Discussion Paper No. 9885, Bonn: IZA.

Burgess S and Wilson D (2005) Ethnic segregation in England's schools. Transactions of the Institute of British Geographers 30(1): 20-36.

Burgess, S, Wilson, D and Lupton, R (2005) Parallel lives? Ethnic segregation in schools and neighbourhoods, Urban Studies, 42(7): 1027-1056

Burgess S, McConnell B, Propper C and Wilson D (2007) The impact of school choice on sorting by ability and socie-economic factors in English secondary education. In: Woessmann L and Peterson P (eds) Schools and the Equal Opportunity Problem. Cambridge, MA: MIT Press. 
Burgess S, Greaves E, Vignoles A and Wilson D (2011) Parental choice of primary school in England: what types of school do different types of family really have available to them? Policy Studies 32(5): 531-547.

Burgess S, Greaves E, Vignoles A and Wilson D (2015) What parents want: school preferences and school choice. Economic Journal 125: 1262-1289.

Butler T and Hamnett C (2010) 'You take what you are given': the limits of parental choice in education in East London. Environment and Planning A 42: 2431-50.

Butler T and van Zanten A (2007) School choice: a European perspective. Journal of Education Policy 22(1): 1-5.

Cooper H (1982) Scientific guidelines for conducting integrative reviews. Review of Educational Research 52(2): 291-302.

Fack G and Grenet J (2010) When do better schools raise housing prices? Evidence from Paris public and private schools. Journal of Public Economics 94: 59-77.

Fowler, F (2002) Introduction: The great school choice debate. The Clearing House 76(1): 4-7.

Frankenberg E (2013) The role of residential segregation in contemporary school segregation Education and Urban Society 45 (5): 548-70

Gibbons S and Machin S (2003) Valuing English primary schools. Journal of Urban Economics 53(2): 197-219. 
Goldthorpe J (1996) Class analysis and the reorientation of class theory: the case of persisting differentials in educational attainment. British Journal of Sociology 47(3): 481504.

Jackson G (1980) Methods for integrative reviews. Review of Educational Research 50(3): 438-460.

Koedel C, Betts J, Rice L, and Zau A (2009) The integrating and segregating effects of school choice Peabody Journal of Education 84 (2): 110-129.

Oberti M (2007) L'école dans la ville: Ségrégation - mixité - carte scholaire Paris: Science Po, Les Presses

O’Campo P, Molnar A, Ng E, Renahy E, Mitchell C, Shankardass K, St John A, Bambra C, Muntaner C (2015) Social welfare matters: A realist view of when, how, and why unemployment insurance impacts poverty and health Social Science and Medicine 132: 88-94.

Pawson R, Greenhalgh T, Harvey G and Walshe K (2005) Realist review - a new method of systematic review for complex policy interventions, Journal of Health Services Research and Policy, 10(Supplement 1): S1: 21-S1: 34.

Raveaud M and van Zanten A (2007) Choosing the local school: middle-class parents' values and social and ethnic mix in London and Paris. Journal of Education Policy 22(1): 107-24. 
van Zanten A and Kosunen S (2013) School choice in five European countries: the circulation of Stephen Ball's concepts and interpretations. London Review of Education 11 (3): 239-255.

Wilson D (2013) Targets, choice and voice: accountability in public services? In: Griffiths, S, Kippin H and Stoker G (eds) Public Services: A New Reform Agenda. London: Bloomsbury Academic Press.

Whittemore R and Knafl K (2005) The integrative review: updated methodology Journal of Advanced Nursing 52(2): 546-553. 
Table 1: Two broad categorisations of school choice system

\begin{tabular}{|c|c|c|c|c|}
\hline & $\begin{array}{l}\text { Types of school to } \\
\text { which pupils } \\
\text { allocated }\end{array}$ & Process of allocation & Method of payment & $\begin{array}{l}\text { Geographical representation of school choice } \\
\text { system in our dataset }\end{array}$ \\
\hline OPT OUT & $\begin{array}{l}\text { - Alternative state } \\
\text { schools } \\
\text { - Semi-autonomous } \\
\text { state schools (eg } \\
\text { charter and magnet } \\
\text { schools in USA) } \\
\text { - Private schools } \\
\text { incorporated in } \\
\text { state-funded choice } \\
\text { system }\end{array}$ & $\begin{array}{l}\text { - Schools as own } \\
\text { admissions } \\
\text { authorities with } \\
\text { particular selection } \\
\text { criteria (sometimes } \\
\text { including top-up fees) } \\
\text { - District-level } \\
\text { allocation rules, eg: } \\
\text { proximity; lottery }\end{array}$ & $\begin{array}{l}\text { - Per capita funding } \\
\text { - Vouchers: } \\
\text { (a) universal - available to } \\
\text { all pupils wanting to opt- } \\
\text { out } \\
\text { (b) targeted - at particular } \\
\text { groups of (disadvantaged) } \\
\text { students; or at students } \\
\text { attending a 'failing' school }\end{array}$ & $\begin{array}{l}\text { North America: } \\
\text { USA: } \\
\text { - National: } 6 \text { papers } \\
\text { - State: } 7 \text { papers (Florida (2); Texas; North Carolina; } \\
\text { Arizona (2); Michigan) } \\
\text { - City: } 12 \text { papers (New York (2); Montgomery } \\
\text { County; Milawukee; Chicago; Charlotte- } \\
\text { Mecklengurg; anonymous urban district; } \\
\text { Washington DC; Philadelphia; Durham NC; San } \\
\text { Diego; Indianapolis) }\end{array}$ \\
\hline
\end{tabular}




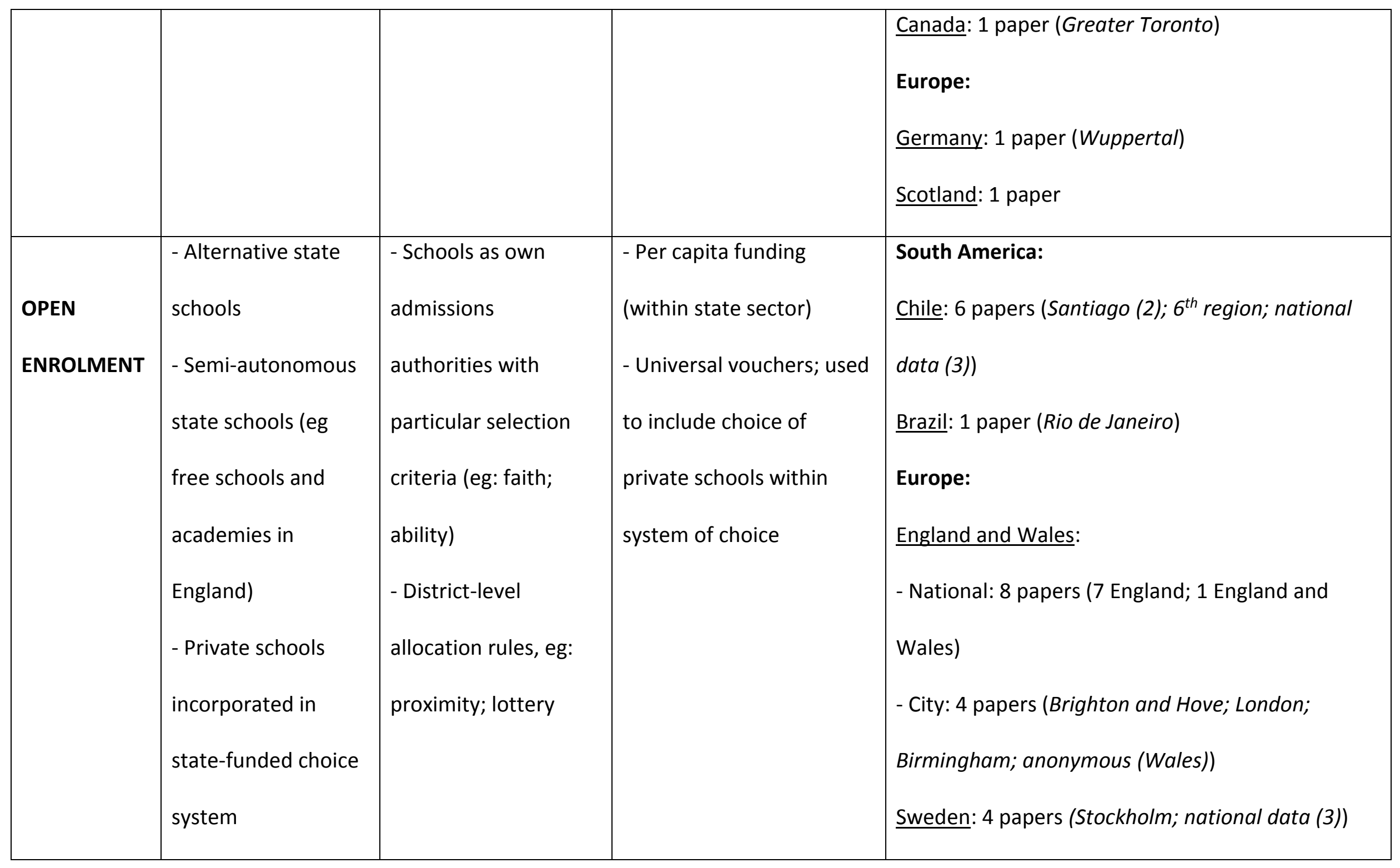




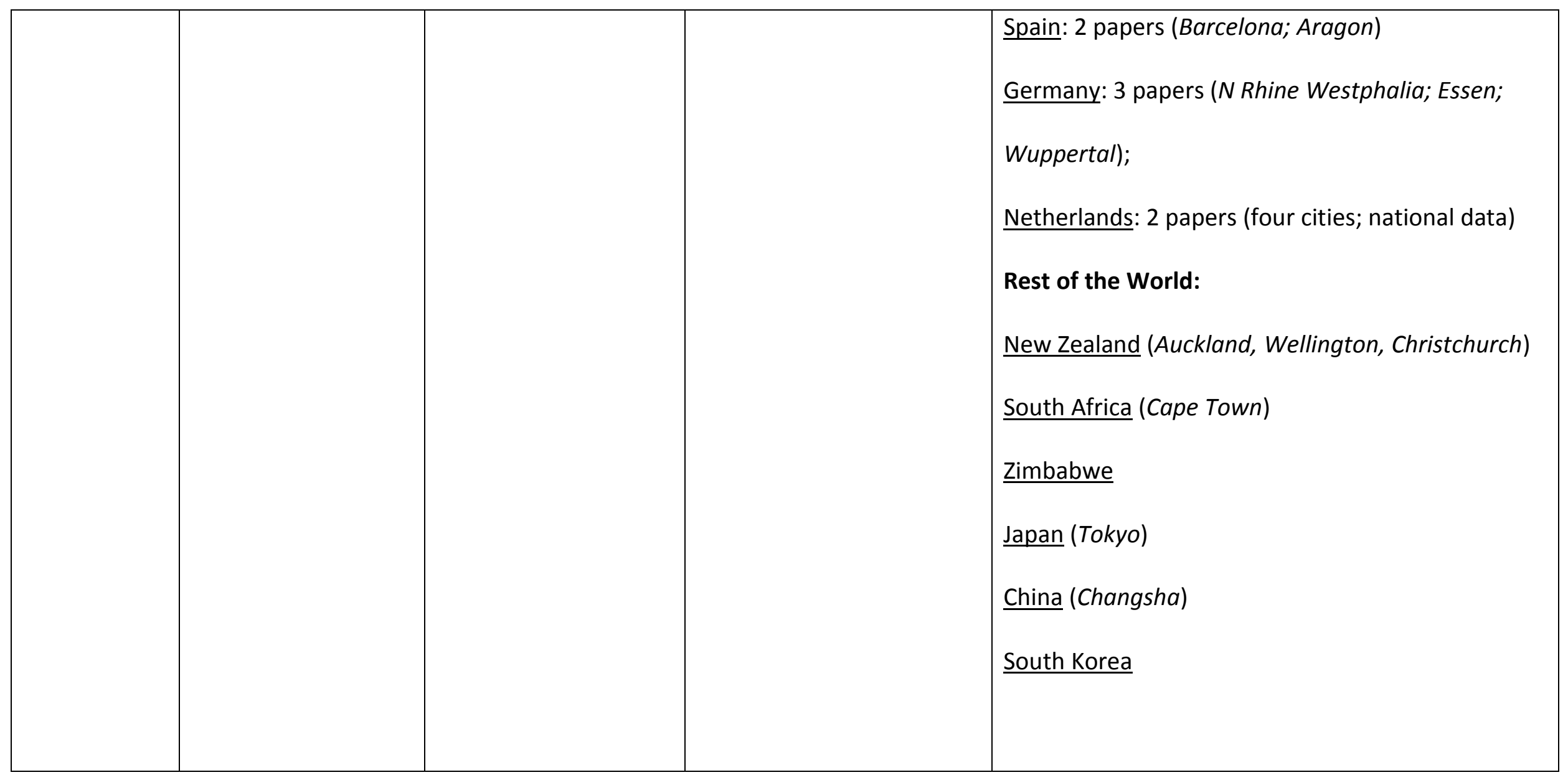


School choice and the city: geographies of allocation and segregation

\section{Technical Appendix}

Table A1: categorization for data extraction

\begin{tabular}{|l|l|}
\hline Column heading & Legend / explanation \\
\hline ID & Unique paper identifier \\
\hline Theoretical/empirical/both & An indicator of type of study \\
\hline Country & Country in which the analysis is situated \\
\hline Location & For example, name of particular city, region \\
\hline Stage of education & \\
\hline Sample & Primary/elementary or secondary/high school \\
\hline Sample size & \\
\hline & Sample drawn on for the purpose of the study \\
\hline & \\
\hline
\end{tabular}




\begin{tabular}{|c|c|}
\hline $\begin{array}{l}\text { Pupil/family characteristics - } \\
\text { categorization }\end{array}$ & Socioeconomic status; ethnicity; gender; faith.... \\
\hline $\begin{array}{l}\text { Pupil/family characteristics - } \\
\text { operationalization }\end{array}$ & $\begin{array}{l}\text { Measures used (for example: family income; } \\
\text { parents' education for social class; self-reported } \\
\text { ethnicity;) }\end{array}$ \\
\hline Quantitative/qualitative/mixed & Indicator of primary research method(s) employed \\
\hline Research design & $\begin{array}{l}\text { For example: survey; interview; statistical analysis } \\
\text { of administrative data... }\end{array}$ \\
\hline Methodological rigour & $\begin{array}{l}\mathrm{H} / \mathrm{L} \text { - see Table } \mathrm{A} 2 \text { below for quality evaluation } \\
\text { criteria }\end{array}$ \\
\hline Theoretical consistency & $\mathrm{H} / \mathrm{L}$ - see Table $\mathrm{A} 3$ below for evaluation criteria \\
\hline Choice system & 1/0 (as explained below) \\
\hline
\end{tabular}




\begin{tabular}{|c|c|}
\hline Key elements & $\begin{array}{l}\text { Description of key features of choice system being } \\
\text { analysed }\end{array}$ \\
\hline Choice set & $1 / 0$ (as explained below) \\
\hline Choice dynamics & $1 / 0$ (as explained below) \\
\hline Notes/comments & $\begin{array}{l}\text { Any additional relevant information regarding } \\
\text { aspects of choice dynamics included in the study }\end{array}$ \\
\hline Actual choice & $1 / 0$ (as explained below) \\
\hline Allocation mechanism & $1 / 0$ (as explained below) \\
\hline Allocation of pupils to schools & $1 / 0$ (as explained below) \\
\hline Authors' findings & Summary of key findings of the study \\
\hline
\end{tabular}




\begin{tabular}{|l|l|}
\hline \multicolumn{1}{|c|}{ implications } & Summary of key implications of the study, as \\
\hline (research; policy) & identified by the authors \\
\hline Reviewer additional comments & Key elements, findings, other comments \\
& \\
\hline
\end{tabular}

\section{Components of the choice process}

Each study was marked $1 / 0$ with reference to the different elements of the choice process as listed below:

1: the study includes information on the element;

0 : the study does not include information on the element.

- The choice system (details of the system also included in the matrix)

- The set of schools that the parents are choosing from (their choice set)

- Choice dynamics - preferences over school attributes and other factors (eg information) that inform parental decisions

- Actual choice - the actual choice that parents make (the 'nominated' school) 
- Allocation mechanism - the part of the choice system that links the actual choice (nomination) to the school to which the pupil is allocated (eg selection criteria; tie-break devices; lottery...)

\section{Methodological rigour}

Studies were not excluded on the basis of any form of ex ante quality evaluation. Rather, as in Table $A 1$, all studies in the dataset were marked $H$ or $L$ to indicate their methodological rigour, informed by the criteria in Table $\mathrm{A} 2$.

$H=$ study conforms to what is required from examples in the table; $L=$ study doesn't conform

Table A2: methodological rigour / quality evaluation criteria

\begin{tabular}{|l|l|}
\hline Study construct & Example \\
\hline Sample & 1 Sampling strategy defined and appropriate \\
& 2 Sample size appropriate for methods employed \\
\hline Study protocol & 1 Study procedures systematic and well justified \\
\hline Measurement & 1 Data collection specified and systematic \\
\hline
\end{tabular}




\begin{tabular}{|c|c|}
\hline & $\begin{array}{l}2 \text { Measures used demonstrate adequate reliability and } \\
\text { validity }\end{array}$ \\
\hline Attrition & $\begin{array}{l}1 \text { Withdrawals, dropouts or other losses from the study } \\
\text { identified and accounted for }\end{array}$ \\
\hline Threats to validity & 1 Confounders and bias considered and controlled \\
\hline Discussion & $\begin{array}{l}1 \text { Conclusions supported by results with possible biases and } \\
\text { limitations considered }\end{array}$ \\
\hline
\end{tabular}

\section{Theoretical consistency}

The review encompassed purely empirical papers as well as purely theoretical papers and empirical papers employing an explicit theoretical framework. ${ }^{4}$ Papers in the latter two categories were marked $\mathrm{H}$ or $\mathrm{L}$ with reference to Table $\mathrm{A} 3$.

\footnotetext{
${ }^{4}$ We do not include the purely theoretical papers in the final dataset on which the current systematic review is based, given our specific focus. We do include both purely empirical papers and empirical papers employing an explicit theoretical framework.
} 
$H=$ study conforms to what is required from examples in the table; $L=$ study doesn't conform.

Table A3: theoretical consistency

\begin{tabular}{|l|l|}
\hline $\begin{array}{l}\text { Theoretical } \\
\text { consistency }\end{array}$ & $\begin{array}{l}\text { For purely theoretical papers: degree to which the } \\
\text { theoretical approaches used in the paper are consistent; } \\
\text { consistently. } \\
\text { For empirical papers employing an explicit theoretical } \\
\text { framework: degree of consistency between theoretical } \\
\text { approach, research design and methods selection; data } \\
\text { management and analysis (where reported); and } \\
\text { presentation and interpretation of findings. }\end{array}$
\end{tabular}




\section{References in the dataset}

[5] Altonji J, Huang C and Taber C (2015) Estimating the cream skimming effect of school choice. Journal of Political Economy 123(2): 266-324

[7] Bartholo TL (2013) Measuring between-school segregation in an open enrolment system: the case of Rio de Janeiro. Journal of School Choice 7: 353-371

[8] Bifulco R and Ladd H (2006) School choice, racial segregation and test-score gaps: evidence from North Carolina's charter school program. Journal of Policy Analysis and Management 26(1): 31-56

[9] Bifulco R, Ladd H and Ross S (2009) Public school choice and integration evidence from Durham, North Carolina. Social Science Research 38: 71-85

[11] Böhlmark A, Holmlund H and Lindahl M (2016) Parental choice, neighbourhood segregation or cream skimming? An analysis of school segregation after a generalized choice reform. Journal of Population Economics 29: 1155-1190

[13] Böhlmark A and Lindahl M (2007) The impact of school choice on pupil achievement, segregation and costs: Swedish evidence, IZA Discussion Paper No 2786

[16] Burgess S, McConnell B, Propper C and Wilson D (2007) The impact of school choice on sorting by ability and socioeconomic factors in English secondary education. In: 
Peterson P and Woessman L (eds) Schools and the Equal Opportunity Problem. Cambridge, MA: MIT Press, pp. 273-291

[17] Burgess S and Briggs A (2010) School assignment, school choice and social mobility. Economics of Education Review 29: 639-649

[18] Burgess S, Johnston R, Key T, Propper C and Wilson D (2008) The transition of pupils from primary to secondary school in England. Transactions of the Institute of British Geographers NS 33 388-403

[20] Byun A, Kim, K and Park H (2012) School choice and educational inequality in South Korea. Journal of School Choice 6(2): 158-183

[24] Chakrabarti R (2013) Do vouchers lead to sorting under random private school selection? Evidence from the Milwaukee voucher program. Economics of Education Review 34: 191-218

[25] Clark, W, Dieleman, F, de Klerk, L (1992) School segregation: managed integration or free choice? Environment and Planning C: Government and Policy, 10: 91-103

[26] Cullen J, Jacob B and Levitt S (2005) The impact of school choice on student outcomes: an analysis of the Chicago public schools. Journal of Public Economics 89: 729760 
[27] Davis T (2014) School choice and segregation: 'tracking' racial equity in magnet schools. Education and Urban Society 46(4): 399-433

[30] Elacqua E (2012) The impact of school choice and public policy on segregation: evidence from Chile. International Journal of Educational Development 32: 444-453

[34] Gallego F and Hernando A (2008) On the determinants and implications of school choice: semi-structural simulations for Chile. Economica 9(1): 197-244

[35] Garcia, D (2008) Academic and racial segregation in charter schools: Do parents sort students into specialized charter schools? Education and Urban Society 40(5): 590-612

[36] Garcia D (2008) The impact of school choice on racial segregation in charter schools, Educational Policy 22(6): 805-829

[42] Gorard S and Fitz J (2000) Markets and stratification: a view from England and Wales. Educational Policy 14(3): 405-428

[44] Green F, Allen R and Jenkins A (2015) Are English free schools socially selective? A quantitative analysis. British Educational Research Journal 41(6): 907-924

[45] Hamnett C and Butler T (2011) 'Geography matters': the role distance plays in reproducing educational inequality in East London. Transactions of the Institute of British Geographers NS 36: 479-500 
[46] Harris R and Johnston R (2008) Primary schools, markets and choice: studying polarization and the core catchment areas of schools. Applied Spatial Analysis and Policy 1: $59-84$

[49] Hastings J and Weinstein J (2008) Information, school choice and academic achievement: evidence from two experiments Quarterly Journal of Economics 123(4): $1373-1414$

[50] Henderson M (2010) Does information help families choose schools? Evidence from a regression discontinuity design, PEPG Working Paper 10-17

[51] Hill LD (2016) Race, school choice and transfers to opportunity: implications for educational stratification in South Africa. British Journal of Sociology of Education. 37(4): $520-547$

[54] Hsieh C and Urquiola M (2006) The effects of generalized school choice on achievement and stratification: evidence from Chile's voucher program. Journal of Public Economics 90: 1477-1503

[55] Jacobs N (2011) Understanding school choice: location as a determinant of charter school racial, economic and linguistic segregation Education and Urban Society 45(4): $459-482$ 
[57] Karsten S, Ledoux G, Roeleveld J, Felix C and Elshof D (2003) School choice and ethnic segregation. Educational Policy 17(4): 452-477

[58] Kristen C (2008) Primary school choice and ethnic school segregation in German elementary schools. European Sociological Review 24(4): 495-510

[59] Ladd $\mathrm{H}$ and Fiske E (2001) The uneven playing field of school choice: evidence from New Zealand. Journal of Policy Analysis and Management 20(1): 43-64

[62] Leonard P (2015) Choice of Ontario high schools and sorting by ability Applied Economics 47(49): 5282-5302

[65] Stein M (2015) Public school choice and racial sorting: an examination of charter schools in Indianapolis. American Journal of Education 121: 597-627

[66] Mancebón-Torrubia M and Ximénez-de-Embún D (2014) Equality of school choice: a study applied to the Spanish region of Aragón Education Economics, 22(1): 90-111

[67] McEwan P, Urquiola,M and Vegas E (2008) School choice, stratification, and information on school performance: lessons from Chile Economica 8(2): 1-42

[72] Valenzuela JP, Bellei C and de los Ríos D (2014) Socioeconomic school segregation in a market-oriented educational system: the case of Chile. Journal of Education Policy 29(2): $217-241$ 
[74] Phillips K, Larsen E and Hausman C (2015) School choice and social stratification: how intra-district transfers shift the racial/ethnic and economic composition of schools. Social Science Research 51: 30-50

[78] Saporito S (2003) Private choices, public consequences: magnet school choice and segregation by race and poverty. Social Problems 50(2): 181-203

[79] Schneider K, Schuchart C, Wieshaupt H and Riedel A (2012) The effect of free primary school choice on ethnic groups: evidence from a policy reform. European Journal of Political Economy 28: 430-444

[82] Söderström M and Uusitalo R (2010) School choice and segregation: evidence from an admission reform Scandinavian Journal of Economics 112(1): 55-76

[84] Taylor C (2009) Choice, competition and segregation in a United Kingdom urban education market. American Journal of Education 115(4): 549-568

[88] Riedel A, Schneider K, Schuchart C and Weishaupt H (2010) School choice in German primary schools: how binding are school districts? Journal for Educational Research Online 2: 94-120 
[93] Hansen KY and Gustafsson J-E (2016) Causes of educational research in Sweden: school choice or residential segregation Educational Research and Evaluation 22(1): 2344

[94] Yoshida A, Kogure K and Ushijima K (2009) School choice and student sorting: evidence from Adachi ward in Japan. The Japanese Economic Review 60(4): 446-472 [103] Makles A and Schneider K (2014) Much ado about nothing? The role of primary school catchment areas for ethnic school segregation: evidence from a policy reform. German Economic Review, 16(2): 203-225

[114] Ilon L (1992) School choice in a privatized market: equity implications in Zimbabwe Journal of Educational Finance 17(4): 303-317

[118] Sikkink D and Emerson M (2008) School choice and racial segregation in US schools: the role of parents' education. Ethnic and Racial Studies 31(2): 267-293

[120] Song Y (2014) Sorting, school performance and quality: evidence from China, mimeo

[122] Weiher G and Tedin K (2002) Does choice lead to racially distinctive schools? Charter schools and household preferences. Journal of Policy Analysis and Management. 21(1): 79-92 
[129] Willms D and Echols F (1992) Alert and inalert clients: the Scottish experience of parental choice of schools. Economics of Education Review 11(4): 339-350

[130] Ni Y (2012) The sorting effect of charter schools on student composition in traditional public schools. Educational Policy 26(2): 215-242

[131] Renzulli L and Evans L (2005) School choice, charter schools, and white flight. Social Problems 52(3): 398-418

[133] Koedel C, Betts J, Rice L and Zau A (2009) The integrating and segregating effects of school choice Peabody Journal of Education 84(2): 110-129

[134] Howell, W (2004) Dynamic selection effects in means-tested, urban school voucher programs. Journal of Policy Analysis and Management 23(2): 225-250

[135] Campbell D, West M and Peterson P (2005) Participation in a national, meanstested school voucher program Journal of Policy Analysis and Management 24(3): 523541

[139] Figlio D, Hart C and Metzger M (2010) Who uses a means-tested scholarship, and what do they choose? Economics of Education Review 29: 301-317

[154] Elacqua G, Schneider M and Buckley J (2006) School choice in Chile: is it class or the classroom? Journal of Policy Analysis and Management 25(3): 577-601 
[156] Calsamiglia C and Güell M (2014) The illusion of school choice: empirical evidence from Barcelona, CEPR Discussion Paper No. 10011, www.cepr.org/pubs.dps/DP10011.php, accessed 26/05/17

[157] Lankford H and Wyckoff J (2001) Who would be left behind by enhanced private school choice? Journal of Urban Economics 50: 288-312

[158] Bradley S and Taylor J (2002) The effect of the quasi-market on the efficiencyequity trade-off in the secondary school sector. Bulletin of Economic Research 54(3): 295-314

[160] Henig J (1996) The local dynamics of choice: ethnic preferences and institutional responses. In: Fuller B, Elmore R and Orfield G (eds) Who Chooses? Who Loses? Culture, Institutions, and the Unequal Effects of School Choice. New York: Teachers College Press, pp: $95-117$

[161] Schneider M, Teske P and Marschall M (2000) Does choice increase segregation and stratification? In: Schneider M, Teske P and Marschall M (eds) Choosing Schools: Consumer Choice and the Quality of American Schools Princeton: Princeton University Press, pp: 204-222

[165] Allen R (2007) Allocating pupils to their nearest secondary school: the consequences for social and ability stratification. Urban Studies 44(4): 751-770 
[168] Allen R, Burgess S and McKenna L (2010) The early impact of Brighton and Hove's school admission reforms, CMPO Working Paper No. 10/244, Bristol: CMPO

[169] Taylor, C (2002) Social equity in the 'new' education market. In: Taylor C (2002) Geography of the 'New' Education Market: Secondary School Choice in England and Wales Aldershot: Ashgate, pp 199-244 